\title{
A TESHUVÁ EM CABELOS DE FOGO DE MARCOS SERRUYA: O SHADAI HERDADO E O RETORNO À CULTURA JUDAICA NA AMAZÔNIA PARAENSE
}

\author{
Alessandra F. Conde Da Silva ${ }^{1}$ \\ Silvia Helena Benchimol-Barros ${ }^{2}$
}

\begin{abstract}
RESUMO
]

O romance mostra a saga de Ana Júlia, judia polonesa, roubada em sua ingenuidade e forçada à prostituição na Amazônia. Ionathan busca na história da bisavó Ana, um documento que a ligasse à cultura judaica na esperança de se provar judeu. A prostituição a mantem distante da comunidade judaica sefardita, mas o bisneto, convicto de sua herança, com os relatos maternos e o Shadai herdado, procura sua teshuvá, e da bisavó, como por expiação. Acham-se ecos do apagamento e do hibridismo cultural vividos pelos judeus na Amazônia desde as primeiras imigrações. Fugidos da perseguição etno-religiosa na Península Ibérica do século XV, muitos erradicaram-se no Marrocos, imigrando para o Brasil. A memória de um passado lusitano ganhou fôlego e ardor fomentados pelo imaginário judeu sefardita. A pertença ao judaísmo buscada por Ionathan reflete o que tantos antepassados procuram preservar. São a esses ecos da judeidade na Amazônia, quer como preservação, quer como retorno cultural que este artigo busca dar conta, a partir da história de Ana e da trajetória de perquirições de Ionathan. Para tal fim, contamos com os apontamentos teórico-históricos de Reginaldo Jonas Heller, Henrique Veltman, Samuel Benchimol, Moacyr Scliar, Paul Johnson entre outros.
\end{abstract}

Palavras-Chave: Cabelos de fogo, de Marcos Serruya; Amazônia paraense; Judeidade.

\begin{abstract}
The novel shows the saga of Ana Julia, Polish Jewish girl deceived and forced into prostitution in the Amazon. Ionathan searches in the past history of Ana, his great-grandmother, any document connecting her to the Jewish culture in the hope of proving himself a Jew. Prostitution will keep her distanced from the Sephardic Jewish community, but Ionathan, conscious of his origins, and holding the inherited Shadai, searches for his and Ana's teshuvah, as in atonement. The book shows signs of deletion and cultural hybridity experienced by Jews in the Amazon, since the first immigration. Escaped from the ethno-religious persecution in the Iberian Peninsula, many Jews eradicated in Morocco, immigrating to Brazil, afterwards. The memory of a Lusitanian past gained strength and fervour fostered by the Jewish Sephardic imaginary. The sense of being Jewish sought by Ionathan reflects what many ancestors try to preserve. These echoes of Jewishness in the Amazon - either as preservation or cultural return movement - are the main focus of this article based on the story of Ana and Ionathan's investigations. For that purpose, we rely on theoretical and historical documents by Reginaldo Jonas Heller, Henrique Veltman, Samuel Benchimol, Moacyr Scliar, Paul Johnson among others.
\end{abstract}

\footnotetext{
${ }^{1}$ Mestre em Estudos Literários pela Universidade Federal do Espírito Santo, doutoranda em Estudos Literários pela Universidade Federal de Goiás. Vinculada ao grupo de pesquisa - que integra a Rede Goiana de Pesquisa sobre a Mulher na Cultura e na Literatura Ocidental da Fapeg - Fundação de Amparo à Pesquisa do Estado de Goiás - "Mulher difamada e mulher defendida no pensamento medieval: textos fundadores", sob a coordenação do Prof. Dr. Pedro Carlos Louzada Fonseca (UFG). E-mail: afcs77@ hotmail.com.

${ }^{2}$ Mestre em Estudos Linguísticos pela Universidade Federal do Pará. Doutoranda em Tradução e Terminologia pelas Universidades de Aveiro e Nova de Lisboa. Vinculada aos grupos de pesquisa - que integra a Rede Goiana de Pesquisa sobre a Mulher na Cultura e na Literatura Ocidental da Fapeg - Fundação de Amparo à Pesquisa do Estado de Goiás - "Mulher difamada e mulher defendida no pensamento medieval: textos fundadores", sob a coordenação do Prof. Dr. Pedro Carlos Louzada Fonseca (UFG) e; Tradução, Alteridades e interculturalidade em narrativas latino-americanas (UFPA), sob a coordenação do Prof. Dr. José Guilherme dos Santos Fernandes. Email: silviabenchimol@ hotmail.com
} 
Keywords : Cabelos de fogo by Marcos Serruya; the Amazon within Pará; Jewishness .

Recebido em: 21/04/ 2017

Aprovado em: 10/05/2017

\section{Introdução}

O pássaro se achega, se achega junto a mim.

Ao fim de dois minutos, o pássaro voou.

O pássaro voando, meu coração chorando.

Deixou-me aqui esperando sem qualquer piedade.

Leonor Scliar-Cabral ${ }^{3}$.

Este artigo é um trabalho conjunto que une o interesse da pesquisa linguística e literária e a emoção autêntica de ser judeu, provar-se judeu e sobreviver judeu em terras amazônicas, ao mesmo tempo em que destaca um capítulo da história da presença feminina no cenário da imigração judaica da comunidade askenazita, na Amazônia, como sujeito defraudado e vitimado. Toma como célula central o romance "Cabelos de fogo", de Marcos Serruya, que por meio da saga e sofrimento de Ana Júlia, uma jovem judia polonesa, descreve a cruel realidade de sua submissão involuntária à prostituição na Amazônia ${ }^{4}$. A história de Ana, conforme descreve o narrador, é-nos revelada a partir das investigações realizadas por Ionathan que, no afã de reencontrar sua identidade judaica, entrega-se à busca de si e de seu passado através de fatos e evidências que o legitimem como judeu. Subjazem ao enredo aspectos históricos que elucidam canais de entrada dos judeus europeus em terras amazônicas, elementos culturais diatópicos e diastráticos, mas também veem-se os ecos da presença sefaradizim na Amazônia. Descendente de pai judeu, Ionathan recebeu as tradições judaicas dos sefaradizim, mas a necessária busca pela origem verdadeiramente judaica, por condição matrilinear, é o que moverá a provar-se judeu.

O romance traz os ecos de não somente um apagamento, mas também de hibridismo cultural que muitas famílias judias passaram nas terras amazônicas desde as primeiras imigrações no início do século XIX. Fugidos da perseguição etno-religiosa ocorrida na Península Ibérica desde o final do século XV, muitos judeus erradicaram-se no Marrocos, por mais de três séculos, imigrando para o Brasil desde os primeiros anos dos oitocentos. Tanto

\footnotetext{
${ }^{3}$ Dísticos pertencentes à canção "Na casa pequenina", de origem judaica, da região do antigo Império Otomano, adaptada ao português "dos romances e canções populares do judeu-espanhol” por Leonor Scliar-Cabral (1990, p. 94), que retrata a triste história de uma judia abandonada por algum amor de juventude, lançando-a na mais profunda dor. Nas palavras da judiazinha, um canto de desamor.

${ }^{4} \mathrm{O}$ romance de Serruya é baseado em fatos reais.
} 
no Marrocos, quanto na Amazônia, a memória de um passado lusitano não se esvaneceu. Na Amazônia, teve novo fôlego, assim como o ardor fomentado pelo imaginário judeu sefardita. Segundo o Rabino Nilton Bonder (2010, p. 11),

\begin{abstract}
diferente do que se apregoa, os judeus costumam acolher as culturas e as identidades com as quais interagem. Atesta isso o ato de adicionar idiomas de sua origem (Hebraico, Ladino, Arbia-Raquitia), além de influências nos costumes, culinária, artes e interesses em geral integrados como parte do patrimônio da cultura dos antepassados. Tal permeabilidade é a grande responsável pela manutenção da identidade e esta medida entre ser refratário e acolhedor ao contexto acaba por estabelecer um novo e criativo diálogo do qual emerge um inédito personagem. Neste particular o judeu sefardita demonstra maestria: ele finca novas raízes entre umbus, sapucaias e andirobas, mas de seu caule ainda verte o látex ancestral (BONDER, 2010, p. 11).
\end{abstract}

O sentimento de pertença ao judaísmo que Ionathan busca provar reflete a judeidade que muitos dos antepassados procuram valorizar e conservar e que alguns de seus descendentes, como Ionathan, seguiram no encalço. São a esses ecos da judeidade na Amazônia, quer como preservação, quer como retorno cultural que este trabalho busca dar conta, a partir da história de Ana e da trajetória de perquirições de Ionathan.

1.

Moacyr Scliar, em $O$ ciclo das águas ${ }^{5}$, apresenta a triste história da bela Esther, roubada de sua vila na Polônia e trazida ao Brasil, ao Rio Grande do sul, para a prostituição. A mesma fábula vê-se em Cabelos de fogo, do paraense, pertencente à comunidade sefardita de Belém, Marcos Serruya. No romance amazônico, a jovem polonesa Hana, no início do século XX, casa-se com Godel, tomado por rico dono de fazendas na América do Sul. Ludibriada, torna-se presa de um infeliz destino a privar-lhe da família, do grupo judaico e do sentimento de pertença à condição judaica. Para além deste violento logro, Hana perde a identidade e a dignidade de mulher. No entanto, a vergonha que a fez afastar-se da

\footnotetext{
${ }^{5}$ A referência à obra de Scliar dá-se, não somente pela similaridade dos enredos, mas pela importância que o autor paraense atribui à dita obra, referenciada na bibliografia utilizada pelo autor para compor o seu "Cabelos de fogo". Naquela, "a protagonista Esther, depois de uma escala em Paris e de uma temporada em Buenos Aires, é instalada num bordel em Porto Alegre, vindo a conceber, posteriormente, um filho com Rafael, jovem a quem inicia sexualmente a pedido do pai dele. Marcos, o filho da prostituta judia, fica aos cuidados da fiel empregada Morena em decorrência da profissão da mãe, e, quando adulto, se torna professor de História Natural. Na narrativa, que começa pelo fim, e é construída em pequenos blocos, as considerações do professor, que fala em primeira pessoa, alternam-se com as cenas em que o vivido, que constitui seu passado, é retomado por um narrador onisciente" (CÁNOVAS, 2011, p. 2014). Em "A condição Judaica" (1985), Scliar, também médico, além de escritor, comenta que foi o contato travado com uma paciente, velha prostituta judia, que o inspirou a escrever sobre Esther e as garotas judias prostituídas pela Tzvi Midal, grupo mafioso judaico do início do século $\mathrm{XX}$.
} 
comunidade sefaradita $^{6}$, em Belém, por sua situação que feria aos princípios do judaísmo, não a impediu de deixar por herança o Shadai familiar e os relatos de sua vida na Shtetl, pequeníssima aldeia judaica na região polonesa. Conhecida como a judia dos cabelos vermelhos, em terras amazônicas, Hana tornou-se Ana. Após anos vivendo em prostituição, a polaca foi auxiliada pelo Intendente Municipal, que conhecera no Amapá e que a ajudara quanto à doação de sua primeira filha. Tornando-se, a seguir, na capital paraense, a senhora do tal intendente, Ana pode viver de modo mais digno, tendo ainda dois filhos. Obrigada a entregar a filha à doação, não antes de dar-lhe a estrela de David e de garantir que a menina deveria ser informada sobre a ascendência judaica da mãe, Ana, com o tempo, adoentada e sob os cuidados de Júlia, sua amiga espanhola, ouviu o Shemá ${ }^{7}$, sem ter conhecido sua filha Joseana.

A história da judia polaca, enganada na juventude e conduzida à prostituição e abandonada grávida pelo português Josiel - que a deixara por uma moça de certa posição social - até encontrar uma remissão no Intendente Municipal, será apresentada por um narrador onisciente que também será conhecedor da trajetória do bisneto de Ana, Ionathan, desejoso de provar-se judeu. Sabedor da narrativa de vida de Ana Júlia, do que ouvira de sua avó e das pessoas que conheceram Ana, Ionathan consegue encontrar um documento que prova que uma mulher, Ana Júlia, entregara sua avó à doação, a um casal cristão, mas não havia qualquer menção sobre uma possível ascendência judaica da mulher. Ainda na sua busca por provas, toma conhecimento do livro de memórias de seu bisavô Josiel. Nele, o português narra o seu caso com a judia de "cabelos de fogo", atestando o nascimento de sua filha Joseana. Ionathan obtém, por fim, a documentação que comprovaria a sua origem judaica. Diz o narrador:

Concluída a coleta de dados e tendo sido entregue o dossiê, a Diretoria do Centro Israelita do Pará, com base no parecer favorável do Rabinato da Comunidade Judaica de Belém, aprovou por unanimidade o resultado da investigação, aceitando oficialmente Dona Helena e todos os seus filhos como judeus legítimos que se submetessem aos rituais costumeiros para que passassem a integrar de fato a Comunidade Israelita do Pará (SERRUYA, 2010, p. 125).

Para a Hallacha, a lei judaica, "ser judeu implica ser filho de mãe judia, (...), ou identificar-se com o judaísmo por algum rabino segundo as restritas leis religiosas do judaísmo ortodoxo" (BENCHIMOL, 2008, p. 175). A intensa investigação de Ionathan para

\footnotetext{
${ }^{6}$ Samuel Benchimol (2008) comenta sobre a presença de judeus askhenazim entre os sefarditas de origem marroquina na Amazônia.

${ }^{7}$ Oração que se costuma recitar no momento da morte.
} 
provar a sua origem judaica e a não aceitação de submeter-se a um batismo, como propusera o Rabino, pois “quem quer se converter, ainda não é” (SERRUYA, 2010, p. 14), mostra o sentimento de judeidade que, no caso de Ionathan, impulsionou uma atitude voltada a restaurar a condição do ser judeu. Dona Helena, mãe de Ionathan, casara com um judeu de descendência marroquina e batizara-se, mas no filho havia um ardor diferente. A herança dos antepassados ainda nele ecoava com grande força, ainda que em sua avó, Joseana, houvesse existido algo da cultura cristã em sua educação, legado que buscou ser abandonado, por sua mãe.

Para entendermos a teshuvá ${ }^{8}$ de Ionathan e indiretamente a de sua bisavó, deveremos considerar, inicialmente, o que precisava ser trazido de volta e em qual ambiência. Descendente de imigrantes ashkenazim, judeus da Europa Oriental, Ionathan, conhecedor de sua história, quer retornar à tradição judaica, direito que fora logrado de sua bisavó. Na comunidade israelita em Belém, em que grande parte dos irmãos eram sefaradi - de origem da Península Ibérica, Ana não se sentia acolhida em razão de sua situação que feria aos princípios éticos e morais da religião e não por sua origem ashkenazi. Considerando a história da formação da Comunidade Israelita na Amazônia, Samuel Benchimol comenta sobre a presença de judeus askenazitas entre os sefaraditas, mas não se cala frente à atitude de exclusão das chamadas polacas, vendidas à prostituição, consideradas tmeyin, impuras (SCLIAR, 1985, p. 100-101):

Quando as judias polacas chegavam à América, Argentina, Brasil e Amazônia, já desvirginadas e não conhecendo o idioma local e não possuindo formação profissional e por serem jovens inexperientes, eram encaminhadas e vendidas para os proprietários de bordéis. Eram marginalizadas e discriminadas pelas comunidades judaicas locais, chegando a ter os próprios cemitérios no Rio de Janeiro e São Paulo (BENCHIMOL, 2008, p. 76).

Na Amazônia, como também no Rio Grande do Sul, como relata Moacyr Scliar (1985, p. 100), ocorreu o tráfico de mulheres brancas ${ }^{9}$, conhecidas como polacas ou francesas; muitas delas eram judias da Rússia ou da Polônia, "no período que vai de 1880 a 1930, aproximadamente”. Serruya como Scliar tomaram este motivo histórico para compor suas narrativas, mas enquanto o primeiro transitará no espaço amazônico, Scliar falará da imigração askenazita no Rio Grande do Sul, considerando, por exemplo, os esforços do Barão Maurice de Hirsch, fundador da “(...) ICA ou JCA (Jewish Colonization Association)"

\footnotetext{
${ }^{8}$ A palavra significa a ideia de retorno à tradição judaica, mas também pode significar arrependimento (HELLER, 2010, p. 111).

${ }^{9}$ Falar da organização criminosa que raptava e gerenciava o tráfico de mulheres.
} 
(SCLIAR, 1985, p. 88), associação filantrópica de auxílio aos judeus fugidos dos pogroms russos.

É significativa na história da imigração judaica no Brasil, a evidência de uma prática iterativa de aculturação, perceptível ao pesquisador desde o movimento de colonização. Restam, ainda hoje, nas regiões norte e nordeste, sobretudo na segunda, resquícios de rituais judaicos, e com base nos primeiros fluxos migratórios do século XIX, no caso amazônico, vêse que também aí, há um desfazimento da cultura judaica e adoção de cultura religiosa outra, no novo espaço de imigração. Para Samuel Benchimol (2008, p. 187), sobre a imigração de judeus na Amazônia,

um número muito grande de famílias judaicas desapareceram para o judaísmo, pois
seus descendentes no interior foram incorporados à massa anônima dos caboclos
empobrecidos, que adotaram o culto católico, evangélico, espiritista e até
umbandista, esquecendo de vez as suas origens ancestrais judaicas. Pelos nossos
cálculos existem, hoje, em toda a Amazônia, cerca de 283.859 Judeus-caboclos,
descendentes dos sefaraditas e forasteiros do Marrocos e de ashkenazitas europeus,
cujas primeiras levas de migrantes chegaram à região a partir de 1810
(BENCHIMOL, 2008, p. 187).

No caso da família de Ionathan, a aculturação sofrida por sua avó será desfeita no bisneto; sua mãe, indiretamente, já se fizera judia convertida, mediante o batismo, ao casar-se com um judeu, isto é, não lhe foi reconhecida a sua origem ancestral judaica. No caso de Ana, o direito de viver e ficar como judia foi-lhe roubado. A condição judaica, "categoria emocional e/ou existencial" (SCLIAR, 1985 , p. 28) tão procurada por Ionathan e a atitude de questionar a validade do batismo, por algum tempo, conduziram-no a realizar uma teshuvá não somente individual, mas familiar. A temática central de "Cabelos de fogo" é a do retorno à condição judaica, da identidade original, do orgulho à tradição hebraica, de uma judeidade, que para Reginaldo Jonas Heller (2010, p. 23), trata-se de “(...) certo sentimento de pertinência a um grupo definido em termos culturais", em nosso caso, à cultura judaica.

Na ambiência amazônica, Heller (2010, p. 139) comenta que a família, para o judaísmo, pode funcionar "como estratégia de preservação da identidade judaica", conectando-se "à prática diária da religião", o que teria conduzido muitas famílias a evitarem o contato com os não judeus. No entanto, a mescla cultural, mediante o casamento foi inevitável, principalmente quando os imigrantes de origem sefaradita vieram à Amazônia sem esposas. No caso de Ana, o matrimônio com os não judeus, ao mesmo tempo, o sentimento de auto-exclusão em relação à comunidade israelita em Belém, não desfizeram os ideais e práticas de sua condição judaica. À beira da morte, diz à amiga de agruras:

Júlia, promete que vai mandar dizer à minha família que me casei, tive três filhos e fui feliz? O endereço e o nome de meus pais estão na gaveta da cabeceira... Mas só diga isso. Não fale do resto. Diga que Godel morreu na viagem e que casei com outro senhor, também judeu. 
A ficcionalização de sua história a ser informada à família é o reconhecimento e desejo do que gostaria de ter vivido, ao menos, da atenuação das desgraças. Ela pode conceber a viuvez, mas não um segundo casamento com um goím, não judeu. Os valores familiares religiosos ecoam numa judia privada de seu direito de ser, viver e ficar judia, como destaca Samuel Benchimol (2008, p. 175). As idas à Sinagoga em Belém comprovam tais ecos:

Para reduzir a sensação de isolamento, tentou aproximar-se da Comunidade Judaica da cidade em que morava. Embora os judeus do Pará sejam, na sua grande maioria, descendentes de sefaraditas marroquinos, seguindo costumes muito diferentes dos judeus poloneses, ela não deixava de comparecer aos ofícios das datas magnas dos hebreus: o Iom Kipur (dia do perdão) e o Rosh Hashaná (ano novo judaico). E também começou a ir às reuniões em alguns sábados. Todavia sempre foi tratada com desconfiança e preconceito pelos frequentadores, que a mantinham sempre a distância. Ninguém falava com ela nada além dos tradicionais cumprimentos: Shabat Shalom (bom sábado!) ou Hág samêach (boa festa!) (SERRUYA, 2010, p. 105).

Retomando as ideias de Benchimol (2008, p. 175), "é muito difícil ser, viver e ficar judeu em qualquer parte do mundo e, sobretudo, na Amazônia", o que não significa que não haverá meios de sanar ou amenizar as dificuldades. Henrique Veltman (2005, p. 61) cita uma pequena narrativa de Sultana Levy Rosemblatt sobre os rituais religiosos judaicos e a busca pela preservação da cultura:

Vale a pena reproduzir uma cena emocionante, narrada pela escritora Sultana Levi, em texto que nos foi entregue por sua prima Anita Levi Soares: "Estava de compras com uma prima, quando ela lembrou que devia ir a uma sinagoga improvisada (no Marajó), onde umas crianças vindas do interior iam ser circuncisadas, e fui com ela. Para minha surpresa, os meninos deviam ter de 9 a 12 anos. Eram três. E os três se aconchegavam um ao outro, calados, trêmulos de medo. Quando um velho de queixo comprido, contando os presentes, anunciou: - Já temos minyam, vamos começar. Desencadeou-se uma verdadeira tourada, ou "com que se prende o touro". Os meninos corriam, gritando, proferindo palavrões, defendendo com as mãos o lugar a ser operado, repetindo, "não me cape, seu desgraçado, seu filho da puta, não me cape". E os homens rindo, corriam atrás, cercavam, fechavam a saída nas portas, até conseguirem agarrar os três. De pés atados, ao som das orações próprias, foram circuncisados, diante de todos e sem qualquer anestesia. Minha prima era chachamá (sábia, estudiosa). Era descendente do grande rabino Eliezer Dabela, de quem herdou poderes sobrenaturais. Sua presença ao ato era necessária, porque ela tinha o dom de acalmar dores com a força de suas preces. Eu me escondi na outra sala, apavorada. Mas não ouvi gritos, pelo contrário, sons de alegria. Dentro em pouco, tudo estava terminado. Quando vieram me chamar para tomar parte na festa, fiquei surpreendida ao ver os três garotos comendo e bebendo entre os convivas. Já então sorriam e pareciam felizes. É que, mesmo vivendo no interior, na selva, eles aspiravam por este dia. Sentiam orgulho de ser judeus. Mas este orgulho não nasceu da liberdade de religião prometida aos imigrantes. Absolutamente. Eles tinham que lutar para manter o seu judaísmo". 
Da mesma forma, Ana buscou lutar pelo seu judaísmo, dadas as circunstâncias. Não houve aculturação religiosa em Ana, mas falta de oportunidade e condições para vivê-lo. Quanto à filha, como já o atestamos, a polaca garantiu que, apesar da adoção, Joseana recebesse o Shadai e que soubesse de sua relação com o judaísmo, indícios para Ionathan de sua origem judaica, além, é claro, da tradição aos ritos judaicos que sempre foram observados pelos pais de Ionathan em sua casa (pai judeu e mãe que adotara a religião do marido). Segundo o narrador, "todos viviam como judeus. Nos ritos domésticos, cumpriam os mandamentos da religião judaica" (SERRUYA, 2010, p. 14). Ionathan se sente judeu, sempre agiu como um; criado como foi, segundo os ritos e tradições judaicos.

Na mesma ideia, vimos que na Amazônia ser judeu nos primeiros momentos de imigração judaica, foi uma atitude de força, de combate às atrativas condições de aculturação ${ }^{10}$. Ionathan é movido pela fé no Deus de seus ancestrais. Tal sentimento ecoava em seu coração fazendo-o lutar por seu lugar entre os filhos de Abraão. Esta mesma certeza imperou nas almas dos primeiros imigrantes judeus, refletindo em ações que buscavam preservar a sua judeidade. Recebendo o ensinamento de seu pai, judeu descendente de marroquinos, Ionathan aprendeu o que é ter uma alma judaica, mesmo que não houvesse, comprovadamente, um ventre judeu que o confirmasse judeu.

2.

Em "Cabelos de fogo", dez capítulos descortinam a história de Ana Júlia. Mas há ainda um prólogo e um epílogo. São neles que o narrador onisciente busca "formar e informar” (RODRIGUES, 2010, p. 12) ao leitor sobre as perquirições e anseios de Ionathan. Aliás, o narrador de "Cabelos de fogo" apresenta uma postura didática, judiciosa, moralizante, à luz de uma interpretação alegórica dos fatos e eventos como cultivada por Fílon, o judeu, nos fins da Antiguidade ${ }^{11}$. Mas, no caso deste narrador, as causas a serem combatidas são as do preconceito e as das exclusões.

\footnotetext{
${ }^{10}$ Para Samuel Benchimol (2008, p. 170), comentando sobre a participação da mulher judia nos primeiros momentos da imigração sefaradita na Amazônia, "a mãe judia, além de ter que ser boa de cama, devia ser boa de cozinha para preparar para o marido e os filhos a tradicional e deliciosa comida sefaradi-marroquina, adaptada aos temperos amazônicos, preparada e servida nos dias de sábado e nos almoços e jantares dos dias festivos". Além disso, elas "eram responsáveis, também, pela manutenção das tradições religiosas, da observância do descanso do Shabat (sábado), da pureza dos alimentos Kasher (observância das leis do Kashrut do Levítico sobre o que se pode e não se deve comer), a preparação das festas e cerimôniasreligiosas (...)" (BENCHIMOL, 2008, p. 169-170).

${ }^{11}$ Segundo Ernst Robert Curtius (1996, p. 265), “no fim da Antiguidade a alegoria adquire novo poder sobre os espíritos, e o judeu Fílon aplica-o ao Antigo Testamento. Desse alegorismo bíblico judaico procede o alegorismo cristão dos Padres da Igreja". Mas o que de fato interessa-nos esclarecer é que, reconhecida a tendência da
} 
Hana foi sepultada no final do antigo cemitério, perto do muro dos fundos, antes da "casa de lavagem" - o local onde os corpos eram purificados antes do sepultamento. As prostitutas e os suicidas eram enterrados sempre junto ao muro de trás dos cemitérios judaicos. E essa regra foi seguida. No entanto, os anos se passaram, as vagas daquele cemitério se esgotaram e outra necrópole foi adquirida. Para máximo aproveitamento daquele campo santo, a casa de tahará (purificação) foi demolida e novos enterros foram feitos no local onde antes existia a construção que foi derrubada. Com isso, o local do túmulo de Ana Júlia perdeu a característica de sítio reservado aos impuros. Esse fato parece querer nos ensinar que o tempo faz com que sejam superados os preconceitos e exclusões. É preciso que o mesmo ocorra em nossas mentes (SERRUYA, 2010, p. 107).

O narrador de "Cabelos de fogo" pretende ser um instruidor. Não deseja somente contar uma história. A cultura judaica é tão importante quanto a história de Ana Júlia ou a de Ionathan:

(...) por meio das cuidadosas descrições do "contador", o leitor passa a ter acesso a espaços geográficos reais, muitos dos quais, no tempo e no espaço, bem distantes dos de nossas vivências. Esse movimento de partilha de saberes percorre todo o texto, contribuindo para o alargamento da visão de mundo do leitor, que acaba se apropriando, também, de conteúdos linguísticos e culturais do povo judeu (RODRIGUES, 2010, p. 12).

São diversas as referências à cultura linguística judaica (hebraica). Marcos Serruya ocupou-se de fornecer ao leitor um glossário e até mesmo referências bibliográficas, mas o narrador manifestou preocupação semelhante, como se vê no trecho abaixo: "O rapaz abriu sua maleta, tirando de dentro uma garrafa de vinho Kosher - vinho preparado de acordo com os preceitos judaicos - e logo um 'Lechaim', um brinde á vida, marcou o noivado" (SERRUYA, 2010, p. 28). Nas orações intercaladas, o narrador dedicou-se a uma prática metalinguística de explicar, traduzir, para o leitor as tradições linguísticas hebraicas, incorporadas na cultura judaica ${ }^{12}$. $\mathrm{O}$ ato de traduzir é um ato que flerta com o didatismo e com o sentimento de simpatia. No primeiro caso, o narrador não somente quer "informar", mas, também, "formar"; no segundo, ele quer diminuir as fronteiras culturais, tornar próximas culturas díspares. Segundo Peter Burke e R. Po-chia Hsia (2009, p. 15), “(...) o entendimento em si é uma espécie de tradução, convertendo os conceitos e as experiências de outras pessoas em seus equivalentes no nosso próprio "vocabulário"”. Dito de outra forma, o estranho tornase doméstico, "visível”, "audível” (BURKE; HSIA, 2009, p. 16).

Há, no entanto, outro sentimento de simpatia que o narrador deseja cultivar: o da revolta à exploração entre irmãos de fé e à violência contra a mulher. Neste último, manifesta-

tradição judaica à alegoria, há a inclinação ao didatismo que o narrador procura explicitamente expressar, mostrando uma postura de rigor rabínico, didascálico, utilizando eventos e fatos como imagens educativas.

${ }^{12}$ Por ilustração, destacamos mais um fragmento em que o narrador se põe a traduzir a cultura linguística dos judeus aos leitores: "Antes de beijá-la e abraçá-la, ao se despedir, sua mãe tirou do pescoço um cordão com uma joia: um Shadai. Uma estrela de David, em ouro" (SERRUYA, 2010, p. 31). 
se, ainda, a comoção pela falta de piedade às mulheres forçosamente condenadas à prostituição. Assim, numa atitude didática, o narrador manifesta no epílogo:

\begin{abstract}
O que mais me surpreende é a constatação de que esta é mais uma história de irmãos explorando irmãos. E que naquela época havia muitas pessoas que foram capazes de assistir ao aviltamento da condição humana de suas irmãs de fé, sem qualquer tentativa persistente de corrigir aquela violência, resgatar as vítimas de seus algozes e assumir a responsabilidade de reintegrá-las ao seio da comunidade (SERRUYA, 2010, p, 124).
\end{abstract}

A óbvia simpatia à história de Ana e a busca de apiedar o leitor quanto às agruras sofridas pela jovem e inocente judia, levaram o narrador a enredar um cenário poético em que a memória de Ana seria preservada por seus descendentes. O narrador, ao assumir a condição de personagem, em dado momento, não se afasta do ardoroso e imperioso didatismo. A imagem do Shadai será tomada como objeto de recordação da antepassada, assim como de restauração da tradição judaica que em algum momento se perdera, mas que fora resgatada. $\mathrm{O}$ Shadai, cujo brilho encanta o narrador, é a imagem da teshuvá dos descendentes de Ana. Ele diz à neta de Ana: "Não quebre a corrente - aconselhei - passe também esse Shadai a uma de suas filhas, junto com toda a história de sua família” (SERRUYA, 2010, p. 126).

Mais do que valorização da memória familiar, ou de reunião à comunidade judaica da Amazônia, o narrador não nos quer deixar esquecer das dores de um cruel destino que muitas mulheres judias, vindas da Polônia ou Rússia, sofreram ao imigrarem para a América do Sul, no início do século XX. O desrespeito, a violência e a aniquilação ao sujeito mulher manifestados nas ações criminosas do grupo de traficantes judeus, pode ser atenuada na disposição do narrador em tornar sempre conhecida a história de Ana. Não calá-la, não desprezá-la, não subtrai-la da história ${ }^{13}$. Ao contrário, rememorar para chorar com ela a perda da inocência, dos sonhos de menina, da condição judaica que tanta a orgulhava. Mas, ao mesmo tempo, o narrador conduz-nos a entender que houve um lugar/tempo de repouso para Ana, quando seus descendentes regressaram ao seio da comunidade judaica em Belém (SERRUYA, 2010, p. 125-126), terra conquistada pelos pioneiros sefaraditas que emigraram do Marrocos desde o início do século XIX, reconhecendo o novo espaço geográfico como um lugar de repouso para o povo de Deus, na Eretz Amazônia, uma nova Canaan.

\footnotetext{
${ }^{13}$ Para Ivaíze Rodrigues (2010, p. 12), “(...) considero [“Cabelos de Fogo”] [como] instrumento de redenção da memória de todas as Hana, Juana, Anna Júlia, e de tantas outras mulheres judias aviltadas em sua dignidade feminina".
} 


\section{REFERÊNCIAS BIBLIOGRÁFICAS}

\section{Fontes primárias:}

SERRUYA, Marcos. Cabelos de Fogo. Edição do Autor. Belém. 2010.

SCLIAR, Moacyr. O ciclo das águas. São Paulo: Círculo do Livro, 1977.

\section{Fontes secundárias:}

BENCHIMOL, Samuel. Eretz Amazônia. Os judeus na Amazônia. Manaus: Valer, 2008.

BONDER, Nilton. Apresentação. In: Judeus do Eldorado: reinventando uma identidade em plena Amazônia. Rio de Janeiro: E-papers, 2010. p. 11-12.

BURKE, Peter; HSIA, R. Po-Chia. A tradução cultural nos primórdios da Europa Moderna. Tradução de Roger Maioli dos Santos. São Paulo: Editora UNESP, 2009.

CÁNOVAS, Suzana Y. L. Machado. O ciclo das águas de Moacyr Scliar. In: Signótica. v. 23, n. 1, p. 213-229, jan./jun. 2011

CURTIUS, Ernst Robert. Literatura européia e Idade Média latina. Tradução de Teodoro Cabral e Paulo Rónai. São Paulo: Hucitec/Edusp, 1996.

HELLER, Reginaldo. Judeus do Eldorado: reinventando uma identidade em plena Amazônia. Rio de Janeiro: E-papers, 2010.

RODRIGUES, Ivaíze. Prefácio. In: SERRUYA, Marcos. Cabelos de Fogo. Edição do Autor. Belém. 2010.

SCLIAR, Moacyr. A condição judaica; das tábuas da lei à mesa da cozinha. Porto Alegre: L\&PM, 1985.

SCLIAR-CABRAL, Leonor. Romances e canções sefarditas (do séc. XV ao XX). Traduzidos do judeu-espanhol. São Paulo: Massao Ohno Editor. 1990.

VELTMAN, Henrique. Os hebraicos na Amazônia. março/2005 - Disponível em : http://www.comiteisraelitadoamapa.com.br/sc/upload/files/Os_Hebraicos_da_Amazonia.pdf 